\title{
Nonsphericity Index and Size Ratio Identify Morphologic Differences between Growing and Stable Aneurysms in a Longitudinal Study of 93 Cases
}

\author{
(D) A. Chien, (D) Mu, X D. Yokota, (D) F. Scalzo, De. Morimoto, and DN. Salamon
}

\begin{abstract}
BACKGROUND AND PURPOSE: Recent studies have strongly associated intracranial aneurysm growth with increased risk of rupture. Identifying aneurysms that are likely to grow would be beneficial to plan more effective monitoring and intervention strategies. Our hypothesis is that for unruptured intracranial aneurysms of similar size, morphologic characteristics differ between aneurysms that continue to grow and those that do not.
\end{abstract}

MATERIALS AND METHODS: From aneurysms in our medical center with follow-up imaging dates in 2015, ninety-three intracranial aneurysms (23 growing, 70 stable) were selected. All CTA images for the aneurysm diagnosis and follow-up were collected, a total of 348 3D imaging studies. Aneurysm 3D geometry for each imaging study was reconstructed, and morphologic characteristics, including volume, surface area, nonsphericity index, aspect ratio, and size ratio were calculated.

RESULTS: Morphologic characteristics were found to differ between growing and stable groups. For aneurysms of $<3 \mathrm{~mm}$, nonsphericity index $(P<.001)$; 3-5 mm, nonsphericity index $(P<.001)$; 5-7 mm, size ratio $(P=.003)$; $>7 \mathrm{~mm}$, volume $(P<.001)$; surface area $(P<.001)$; and nonsphericity index $(P=.002)$ were significant. Within the anterior communicating artery, the nonsphericity index $(P=.008)$ and, within the posterior communicating artery, size ratio $(P=.004)$ were significant. The nonsphericity index receiver operating characteristic area under the curve was 0.721 for discriminating growing and stable cases on the basis of initial images.

CONCLUSIONS: Among aneurysms with similar sizes, morphologic characteristics appear to differ between those that are growing and those that are stable. The nonsphericity index, in particular, was found to be higher among growing aneurysms. The size ratio was found to be the second most significant parameter associated with growth.

ABBREVIATIONS: $\mathrm{ACA}=$ anterior communicating artery; $\mathrm{BA} / \mathrm{VA}=$ basilar artery/vertebral artery; $\mathrm{ICH}=$ intracerebral hemorrhage; $\mathrm{NSI}=$ nonsphericity index; PcomA $=$ posterior communicating artery

B ecause part of the population has asymptomatic, unruptured intracranial aneurysms $(1 \%-3 \%)$, they are regularly incidentally detected with medical imaging. ${ }^{1,2}$ An appropriate course of monitoring or intervention must then be decided. While this de-

Received August 13, 2017; accepted after revision November 13.

From the Departments of Radiological Science (A.C., M.X., H.Y., E.M., N.S.) and Neurology (F.S.), David Geffen School of Medicine at the University of California, Los Angeles, Los Angeles, California.

This work was supported, in part, by a Brain Aneurysm Foundation Research Grant; a Society of Interventional Radiology Foundation Dr. Ernest J. Ring Academic Development Grant; and a University of California, Los Angeles Radiology Exploratory Research Grant.

Paper previously presented, in part, at: Annual Meeting of the American Society of Neuroradiology, Washington, DC; May 21-26, 2016.

Please address correspondence to Aichi Chien, PhD, Department of Radiological Science, David Geffen School of Medicine at UCLA, 10833 LeConte Ave, Box 957350, Los Angeles, CA 90095; e-mail: aichi@ucla.edu

三 Indicates article with supplemental on-line table.

http://dx.doi.org/10.3174/ajnr.A5531 cision is relatively straightforward for larger intracranial aneurysms $(>7 \mathrm{~mm})$, the best approach for smaller aneurysms is less clear. Recent studies have found a positive correlation between aneurysm growth and rupture. ${ }^{3-6}$ Therefore, it would seem beneficial to identify small aneurysms likely or unlikely to grow and plan treatment/monitoring strategies accordingly.

An unruptured aneurysm may be detected at any size when it becomes symptomatic or incidentally detected through imaging. Currently, from such a snapshot, it is difficult to guess the natural history of an aneurysm: Is it relatively new and rapidly growing or has it gradually increased in size; is it still growing or relatively stable? At present, there is no clear information to predict whether an aneurysm will continue to grow, while certain factors, such as anatomic location, correlate with significantly increased rupture risk. ${ }^{7}$ The objective of this research was to address whether aneurysm morphologic characteristics, size and shape, may provide an additional means of identifying future growth. 


\begin{tabular}{|c|c|c|c|}
\hline & \multicolumn{3}{|c|}{ Aneurysm Growth } \\
\hline & Yes & No & Total \\
\hline \multicolumn{4}{|l|}{ Patients } \\
\hline No. of patients & 23 & 62 & 85 \\
\hline No. of women & 20 & 49 & 69 \\
\hline No. of men & 3 & 13 & 16 \\
\hline Mean age (yr) & $63.6 \pm 15.5$ & $65.9 \pm 11.9$ & $65.2 \pm 12.9$ \\
\hline Atrial fibrillation & 2 & 3 & 5 \\
\hline Cancer & 3 & 8 & 11 \\
\hline Coronary artery disease & 1 & 3 & 4 \\
\hline Diabetes mellitus & 4 & 9 & 13 \\
\hline Dyslipidemia & 6 & 32 & 38 \\
\hline Family history of intracranial aneurysm & 0 & 3 & 3 \\
\hline History of TIA & 2 & 2 & 4 \\
\hline History of ICH & 1 & 1 & 2 \\
\hline History of stroke & 0 & 3 & 3 \\
\hline Hypertension & 12 & 32 & 44 \\
\hline Hypothyroid & 4 & 12 & 16 \\
\hline Previous or current cigarette smoking & 3 & 16 & 19 \\
\hline Previous SAH & 2 & 2 & 4 \\
\hline Seizure & 2 & 1 & 3 \\
\hline \multicolumn{4}{|l|}{ Cases } \\
\hline Aneurysms & 23 & 70 & 93 \\
\hline Average follow-ups & $2.35 \pm 1.15$ & $2.93 \pm 2.45$ & $2.78 \pm 2.21$ \\
\hline Follow-up time (mo) & $46.4 \pm 29.4$ & $51.6 \pm 46.2$ & $50.3 \pm 42.6$ \\
\hline ACA & 4 & 16 & 20 \\
\hline ICA & 8 & 38 & 46 \\
\hline MCA & 1 & 8 & 9 \\
\hline PcomA & 9 & 4 & 13 \\
\hline $\mathrm{BA} / \mathrm{VA}$ & 1 & 4 & 5 \\
\hline Sidewall aneurysm & 19 & 58 & 77 \\
\hline Bifurcation aneurysm & 4 & 12 & 16 \\
\hline \multicolumn{4}{|l|}{ Imaging studies } \\
\hline All & 73 & 275 & 348 \\
\hline$<3 \mathrm{~mm}$ & 21 & 74 & 95 \\
\hline $3-5 \mathrm{~mm}$ & 25 & 135 & 160 \\
\hline $5-7 \mathrm{~mm}$ & 15 & 50 & 65 \\
\hline$>7 \mathrm{~mm}$ & 12 & 16 & 28 \\
\hline $\mathrm{ACA}$ & 15 & 59 & 74 \\
\hline ICA & 25 & 152 & 177 \\
\hline MCA & 7 & 29 & 36 \\
\hline PcomA & 26 & 9 & 35 \\
\hline BA/VA & 2 & 24 & 26 \\
\hline
\end{tabular}

there is an association between aneurysm growth and rupture, these indices were chosen for this study. ${ }^{3,5,6}$ Because this study analyzed longitudinal data, in addition to comparing morphologic indices for aneurysms at diagnosis and grouped by location, aneurysm imaging studies were segregated by size.

\section{MATERIALS AND METHODS Case Information}

This study was performed the with approval of the institutional review board. It was a retrospective analysis of intracranial aneurysm cases with follow-up imaging in the data base of our medical center. All the CT angiograms were acquired on the basis of an established clinical imaging protocol for brain aneurysm follow-up, to ensure consistency for clinical aneurysm management. $^{21,22}$ Ninety-three intracranial aneurysms (23 growing, 70 stable) from 2010 to 2015 with at least 1 imaging follow-up were selected. An aneurysm was classified as growing if it exhibited a $>0.6-\mathrm{mm}$ increase in diameter measured in all subsequent imaging studies. CTA images at each time point for aneurysm diagnosis and follow-up were collected. A total of 348 CTA volumetric imaging sets were included. Aneurysms were followed for a mean of $50.3 \pm 42.6$ months, with a mean of $2.78 \pm 2.21$ follow-up imaging dates, for a mean of $3.35 \pm 1.35$ imaging studies per aneurysm case. Patient information and aneurysm characteristics, including location, aneurysm type, and imaging study numbers, are summarized in Table 1 .
During the past decade, many imaging-derived indices have been proposed for assessing aneurysm risk, primarily focused on identifying differences between ruptured and unruptured aneurysms. ${ }^{8-12}$ These indices include a broad variety of metrics, some of which, like wall shear stress or the pulsatility index, are calculated through computational simulation. ${ }^{13-16}$ However, to date, there have been few studies of aneurysm growth that focus on imagingderived indices. ${ }^{17,18}$ For this research, we focused on morphologic characteristics, which, as a group, are directly calculated from $2 \mathrm{D} / 3 \mathrm{D}$ images without simulation. As a result, these types of indices are simpler to use and more easily applied to larger sample sizes.

The simplest morphologic characteristic describing an aneurysm is its size, typically represented by its maximum diameter. ${ }^{2}$ Indices investigated in this study include volume, surface area, the nonsphericity index (NSI), aspect ratio, and size ratio. ${ }^{9,19,20}$ While these represent a small selection of previously published indices, they all have previously been identified as having some predictive value for discriminating ruptured/unruptured aneurysms; therefore, because

\section{Image Processing and Analysis}

For each aneurysm, 3D geometry for each imaging study was reconstructed and basic morphologic characteristics such as volume and surface area were calculated. ${ }^{23,24}$ From these, the NSI was calculated. Aspect ratio and size ratio were based on manual measurements made by a skilled radiologist who was blinded to whether aneurysms were growing or stable. Figure 1 shows the formulas used for calculation of the indices as well as a depiction of where various shapes fall within the range of values, because this is sometimes difficult to decipher from the formula. As mentioned above, for analysis, the imaging studies were divided into 4 categories ( $<3 \mathrm{~mm}, 3-5 \mathrm{~mm}, 5-7 \mathrm{~mm}$, and $>7 \mathrm{~mm}$ ). Growing and stable aneurysms were also grouped for analysis by general anatomic location (anterior communicating artery [ACA], ICA, MCA, posterior communicating artery [PcomA], or basilar artery/vertebral artery $[\mathrm{BA} / \mathrm{VA}]$ ) and type of aneurysm (sidewall or bifurcation). 


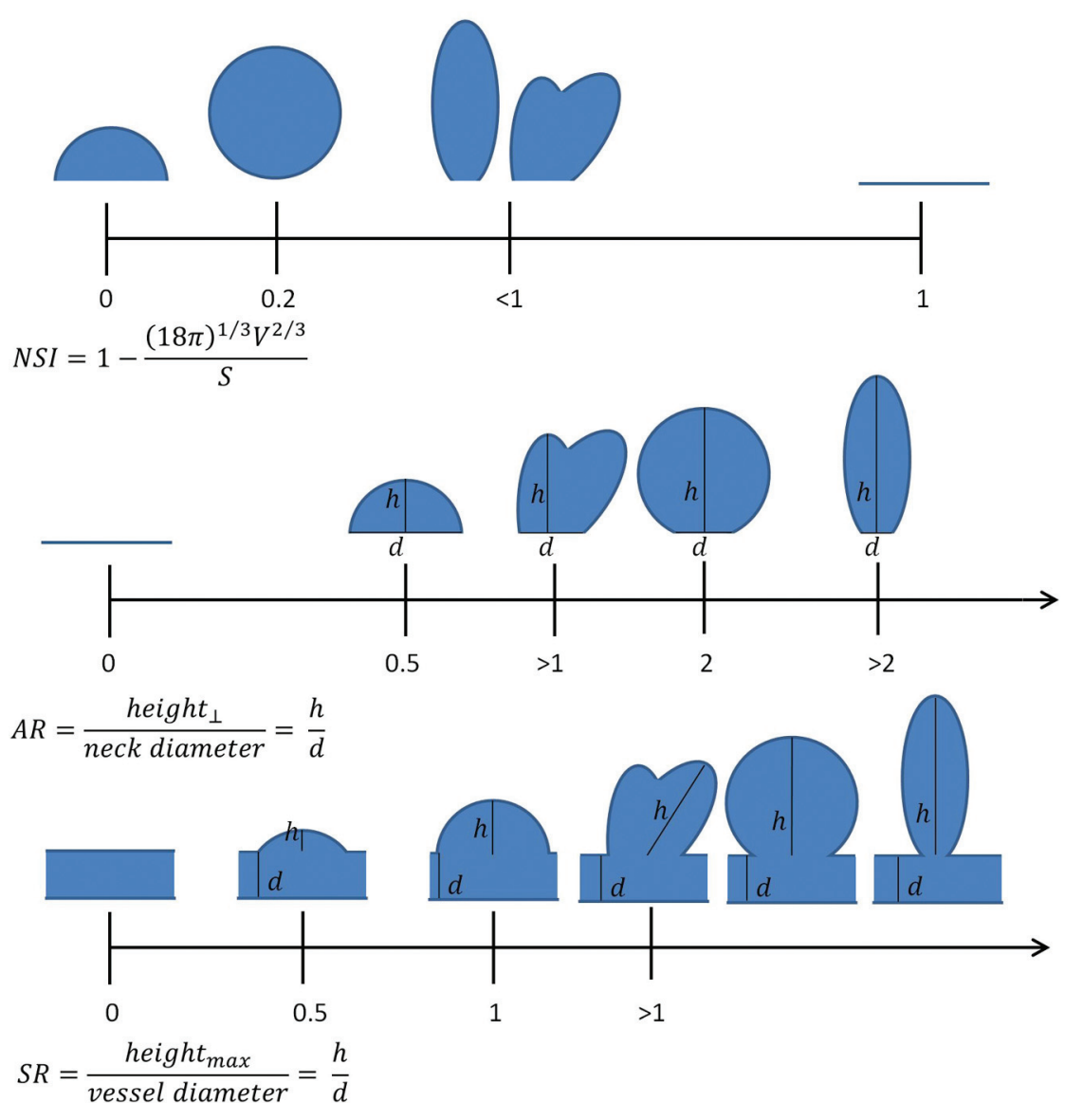

FIG 1. Morphologic indices used in this study, in addition to maximum diameter, volume, and surface area. Formulas for their calculation, along with diagrams illustrating the relative position of various shapes on the different scales are shown. Horizontal lines indicate no aneurysm; AR, aspect ratio; SR, size ratio; max, maximum. The NSI ranges from 0 to 1 and is based on 3D geometry, while the AR and SR start at zero but have no fixed upper limit. Only SR incorporates the size of the parent artery into the calculation.

\section{Statistical Analysis}

Statistical comparisons between growing and stable groups were made using a 2-tailed $t$ test with an assumption of unequal variance (Welch $t$ test). The Pearson $\chi^{2}$ test was used to compare patient information between groups (Table 1). For all statistical analyses, a significant $P$ value was .01. Statistical analysis was performed and figures were prepared in SPSS 24 (IBM, Armonk, New York) and Excel (Microsoft, Redmond, Washington).

\section{RESULTS}

\section{Aneurysm Size versus Morphology}

No significant differences in patient information were found between growing and stable aneurysm groups (Table 1). Statistical analysis identified different morphologic indices as significant when examining different groups of images. Measurements for growing and stable aneurysm images segregated by size are summarized in Table 2. For very small aneurysms ( $<3 \mathrm{~mm})$, the NSI $(P<.001)$ was significantly different between growing and stable groups. For aneurysms of $3-5 \mathrm{~mm}$, only the NSI was significant as well $(P<.001)$. For aneurysms of $5-7 \mathrm{~mm}$, only the size ratio was significant $(P=.003)$. For large aneurysms $(>7 \mathrm{~mm})$, volume $(P<.001)$, surface area $(P<.001)$, and NSI $(P=.002)$ were significantly different among the groups. When we considered all diagnoses and follow-up time points together, volume $(P<.001)$, surface area $(P<.001)$, and the NSI $(P<.001)$ were significant. Finally, when considering only the initial imaging study for each aneurysm, effectively examining all aneurysm cases at diagnosis, only the NSI $(P=.003)$ was significant for growing versus stable. In all analyses in which the NSI was significant, it was consistently higher in the growing group versus the stable group. Figure 2 presents boxplots of the NSI for the growing and stable groups segregated by size.

Receiver operating characteristic curves were plotted for the various indices for growing versus stable (Fig 3). When all imaging studies for all aneurysms were included, the NSI provided superior discrimination between groups, with the area under the curve of 0.712 versus indices such as surface area (area under the curve $=0.638$ ). When only the initial imaging study from all aneurysms was included, the NSI was again superior to the other indices (area under the curve $=0.721$ ).

\section{Aneurysm Location versus Morphology and Aneurysm Type versus Morphology}

Results from comparing growing and stable aneurysms by location are summarized in Table 3. Within the ACA, the NSI $(P=.008)$ was significantly different between growing and stable aneurysms. Although no significant differences were found among ICA aneurysm groups, a trend toward a difference in the NSI $(P=.014)$ was observed. The size ratio $(P=.004)$ was significantly different between groups of aneurysm images within the PcomA. MCA and BA/VA imaging studies were excluded from the location analysis because of insufficient growing aneurysms. In the analysis of growth in bifurcation and sidewall aneurysms ( $17 \%$ and $83 \%$ of total cases, respectively; Table 1 and On-line Table), the NSI was the only significant factor between growing and stable in sidewall aneurysms $(P=$ .006) (Table 4).

\section{DISCUSSION}

Several common morphologic indices for describing aneurysms are highly dependent on diameter, such as volume, surface area, aspect ratio, and size ratio (aspect ratio and size ratio calculate a ratio on the basis of the aneurysm neck and parent artery diameter, respectively, characteristics typically much less variable than aneurysm height) (Fig 1). ${ }^{19,20}$ Indices such as the NSI are independent of aneurysm diameter and, while slightly more complicated to calculate, in exchange provide more robust shape characterization and, on the basis of this study, appear to provide 
Table 2: Index values for growing and stable aneurysms segregated by size ${ }^{a}$

\begin{tabular}{|c|c|c|c|c|c|c|}
\hline & \multicolumn{6}{|c|}{ Index } \\
\hline & $<3 \mathrm{~mm}(n=95)$ & $3-5 \mathrm{~mm}(n=160)$ & $5-7 \mathrm{~mm}(n=65)$ & $>7 \mathrm{~mm}(n=28)$ & $\mathrm{All}^{\mathrm{b}}(n=348)$ & Initial $^{c}(n=93)$ \\
\hline \multicolumn{7}{|c|}{ Maximum diameter } \\
\hline Growing & $2.21 \pm 0.66$ & $3.93 \pm 0.58$ & $6.09 \pm 0.58$ & $8.55 \pm 1.28$ & $4.64 \pm 2.33$ & $3.98 \pm 2.09$ \\
\hline Stable & $2.22 \pm 0.55$ & $3.82 \pm 0.52$ & $5.77 \pm 0.58$ & $8.78 \pm 1.52$ & $4.03 \pm 1.78$ & $4.14 \pm 1.84$ \\
\hline \multicolumn{7}{|l|}{ Volume } \\
\hline Growing & $9.41 \pm 8.51$ & $49.2 \pm 49.7$ & $151 \pm 119$ & $572 \pm 287^{\mathrm{d}, \mathrm{e}}$ & $145 \pm 235^{\mathrm{d}, \mathrm{e}}$ & $110 \pm 197$ \\
\hline Stable & $12.5 \pm 6.88$ & $30.4 \pm 20.9$ & $108 \pm 68.9$ & $150 \pm 261^{d}$ & $46.7 \pm 81.0^{d}$ & $57.0 \pm 106$ \\
\hline \multicolumn{7}{|l|}{ Surface area } \\
\hline Growing & $28.1 \pm 15.9$ & $75.1 \pm 49.4$ & $144 \pm 85.6$ & $384 \pm 165^{\mathrm{d}, \mathrm{e}}$ & $126 \pm 146^{\mathrm{d}, \mathrm{e}}$ & $105 \pm 133$ \\
\hline Stable & $30.0 \pm 13.2$ & $50.6 \pm 26.4$ & $122 \pm 60.4$ & $116 \pm 140^{d}$ & $61.9 \pm 57.4^{d}$ & $70.1 \pm 69.5$ \\
\hline \multicolumn{7}{|l|}{ NSI } \\
\hline Growing & $0.45 \pm 0.08^{\mathrm{d}, \mathrm{e}}$ & $0.36 \pm 0.10^{\mathrm{d}, \mathrm{e}}$ & $0.26 \pm 0.05$ & $0.31 \pm 0.08^{\mathrm{d}, \mathrm{f}}$ & $0.36 \pm 0.11^{\mathrm{d}, \mathrm{e}}$ & $0.38 \pm 0.11^{\mathrm{d}, \mathrm{f}}$ \\
\hline Stable & $0.31 \pm 0.14^{d}$ & $0.27 \pm 0.10^{d}$ & $0.29 \pm 0.09$ & $0.22 \pm 0.03^{d}$ & $0.28 \pm 0.11^{d}$ & $0.29 \pm 0.12^{d}$ \\
\hline \multicolumn{7}{|l|}{ Aspect ratio } \\
\hline Growing & $0.89 \pm 0.54$ & $0.91 \pm 0.33$ & $1.21 \pm 0.34$ & $1.21 \pm 0.27$ & $1.03 \pm 0.43$ & $1.01 \pm 0.54$ \\
\hline Stable & $0.90 \pm 0.24$ & $0.99 \pm 0.29$ & $1.09 \pm 0.33$ & $1.27 \pm 0.81$ & $1.00 \pm 0.34$ & $1.02 \pm 0.40$ \\
\hline \multicolumn{7}{|l|}{ Size ratio } \\
\hline Growing & $0.56 \pm 0.25$ & $0.94 \pm 0.31$ & $2.93 \pm 1.3^{\mathrm{d}, \mathrm{f}}$ & $2.48 \pm 0.71$ & $1.49 \pm 1.20$ & $1.21 \pm 0.91$ \\
\hline Stable & $0.70 \pm 0.30$ & $1.05 \pm 0.34$ & $1.63 \pm 0.59^{d}$ & $1.96 \pm 1.11$ & $1.11 \pm 0.59$ & $1.19 \pm 0.68$ \\
\hline
\end{tabular}

${ }^{a}$ Data are presented as mean $\pm \mathrm{SD}$

b The "All" column includes all imaging studies for all cases.

"The "Initial" column includes the first imaging study for all cases.

${ }^{\mathrm{d}}$ Significant difference between groups.

e $P<.001$

${ }^{\mathrm{f}} P<.01$.

more consistent growth prediction. ${ }^{8,9}$ For all except the smallest aneurysms, volume and surface area were larger for growing aneurysms than stable aneurysms, though this was only significant among large $(>7 \mathrm{~mm})$ aneurysms and when all aneurysm imaging studies were considered. These indices not being significant among smaller aneurysms may indicate that differences in aneurysm morphology are more pronounced for larger aneurysms (Table 2).

When the NSI was significantly different between growing and stable groups, it was consistently higher in the growing group. Referring to Fig 1, this higher NSI corresponds to the growing aneurysms having a more irregular shape. If one considers the association previous studies have found between growth and rupture, a higher NSI among growing aneurysms is consistent with previous findings of a higher NSI among ruptured aneurysms. ${ }^{9,10,25}$ When we further considered morphologic differences among aneurysm sizes, aneurysms of 5-7 mm were found, in general, to be less irregular (more spheric) than smaller or larger aneurysms, as indicated by the NSI values. A plausible explanation for this finding is that aneurysms in this size range are close to the treatment threshold and the more irregular cases were treated instead of being followed with imaging. Among the locations, MCA aneurysms were the least irregular, with PcomA aneurysms having the most convoluted and complex shapes (Table 3). This finding might be due to fewer cases in these locations and the influence of treatment preferences. Because bifurcation aneurysms are usually considered to have a high rupture risk, in our study, $83 \%$ of the cases were sidewall aneurysms. Previous work by Baharoglu et $\mathrm{al}^{12}$ showed the NSI to be associated with rupture in bifurcation aneurysms. In this study, we found the NSI to be significantly higher in growing sidewall aneurysms, while it was not significantly different in bifurcation aneurysms, possibly due to the relatively small percentage of bifurcation cases. This finding may also be because the current study investigated the growth of a low-risk group of aneurysm cases with an average size of $4 \mathrm{~mm}$, while the study of Baharoglu et $\mathrm{al}^{12}$ was focused on aneurysms with high rupture risk, on average $7 \mathrm{~mm}$. The NSI values recorded in this study were higher than values previously reported by other researchers for intracranial aneurysms. ${ }^{9,10,17}$ The reason is unclear but may be due to the smoothing of reconstructed aneurysm geometry, or a lack thereof, before calculation of aneurysm volume and surface area.

Because aneurysms may be detected at any point during their natural history, when one considers longitudinal data, each imaging study may contribute additional information. From the perspective of natural history, there is not anything special about the initial images of an asymptomatic unruptured aneurysm versus images obtained at follow-up. There may, however, be differences among the longitudinal images, due to growth or simply the details of the image acquisition. In the current research, the rationale for performing most of the statistical analyses at the level of the imaging study instead of the aneurysm case was to better identify predictors that might be applied to evaluate initial diagnostic images in combination with size, currently a major criterion for treatment/follow-up decisions. This research supports aneurysm growth being predicted by the same morphologic characteristics previously shown to be significant for rupture, specifically NSI.

The results of this study contrast with a previous, multicenter prospective study that investigated the ability of various indices to predict subsequent aneurysm growth. ${ }^{17}$ Beyond the prospectiveversus-retrospective study design and single time point versus multiple time point image analysis, there are several differences that might explain the apparent discrepancy. First and foremost, the criteria for growth were different between the 2 studies, with the current study relying on a fixed size threshold $(0.6 \mathrm{~mm})$ confirmed by subsequent images and Ramachandran et $\mathrm{al}^{17}$ using expert clinician review. Second, the follow-up duration was con- 
Aneurysms $<3 \mathrm{~mm}(\mathrm{n}=95)$

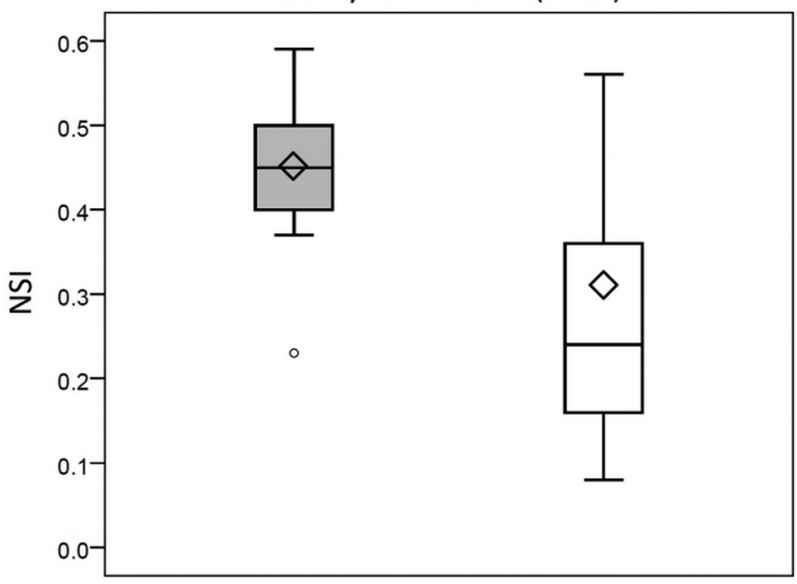

Aneurysms 5-7 mm ( $n=65)$

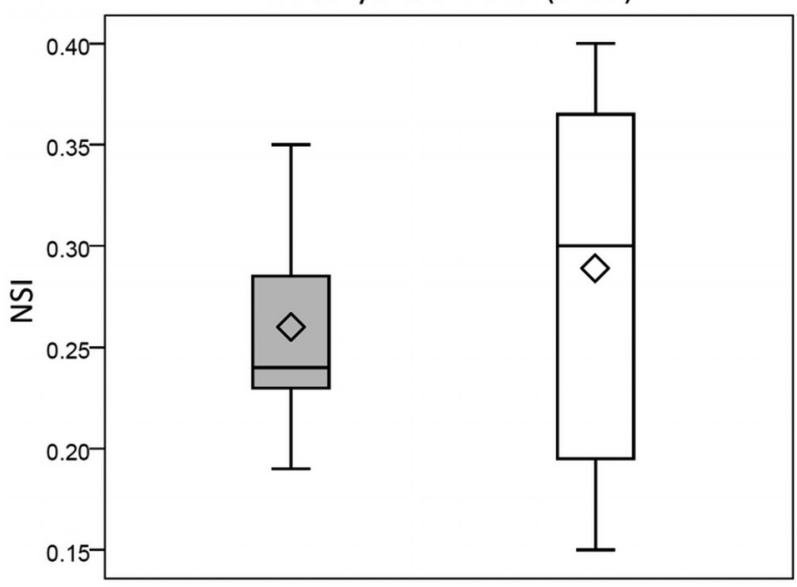

All imaging studies, all aneurysms $(n=348)$

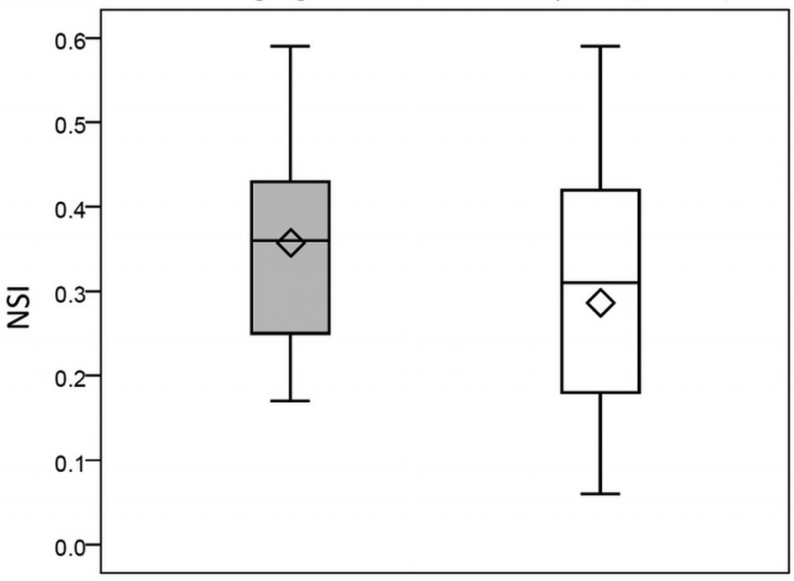

Aneurysms 3-5 mm ( $\mathrm{n}=160)$

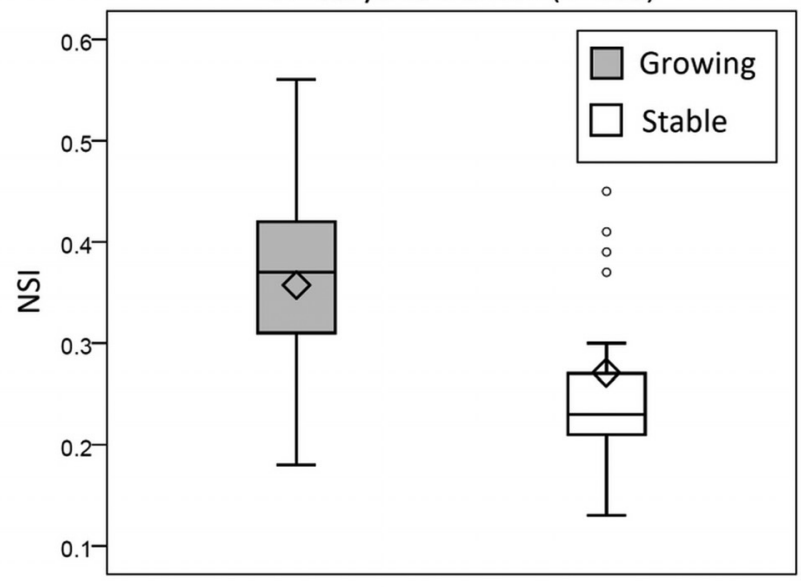

Aneurysms $>7 \mathrm{~mm}(\mathrm{n}=28)$

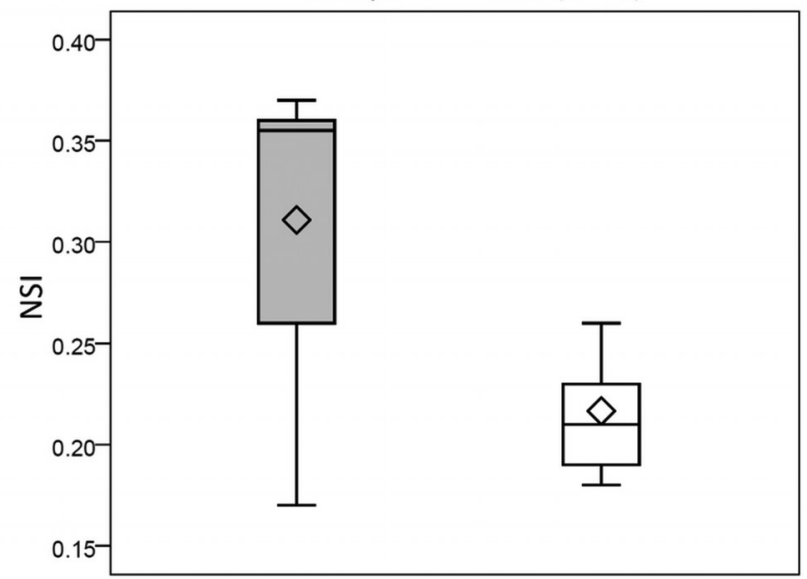

Initial imaging study, all aneurysms ( $n=93)$

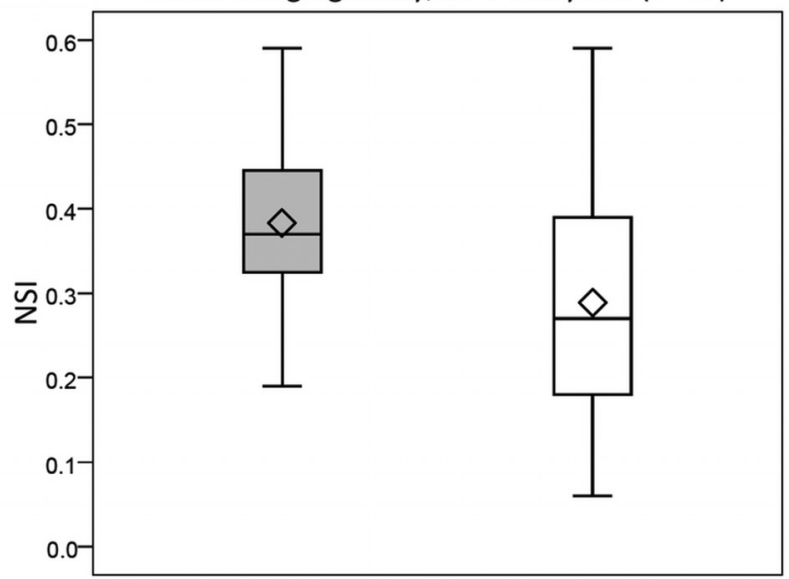

FIG 2. The NSI for imaging studies segregated by size (Tukey boxplots). Shaded and unshaded bars represent growing and stable groups, respectively, in each panel. Diamonds indicate the mean for each group; and the small circles, outliers.

siderably longer in the current study (an average of approximately 4-versus-2 years). Given the growth rates observed in our population sample, many of the aneurysms in the current study would have been incorrectly classified as stable with only a 2-year followup. In some combination, these differences in study design may be responsible.

As the receiver operating characteristic curves illustrate (Fig 3), for our population sample, the NSI was able to more consistently discriminate growing and stable aneurysms on the basis of the initial imaging study than aneurysm diameter or other shape indices. The NSI therefore appears to be a useful metric for identifying aneurysms likely to continue to grow, and we hope to eventually see it incorporated into aneurysm management decisions. Growth studies require longitudinal datasets and consequently require the analysis of many more sets of images. Because morphologic characterization of aneu- 


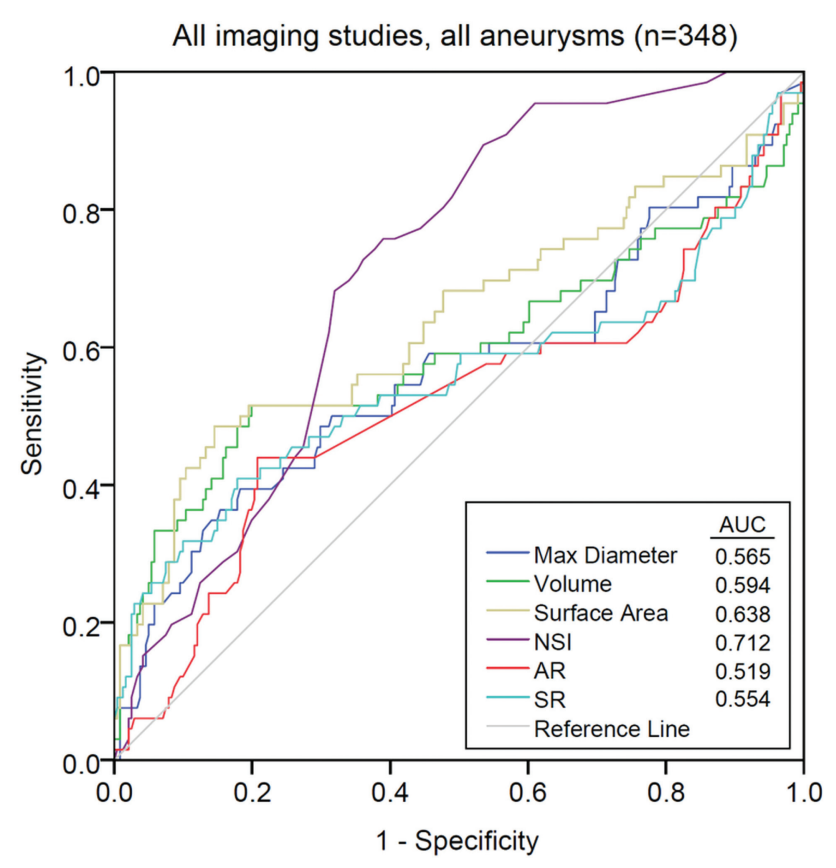

Initial imaging study, all aneurysms $(n=93)$

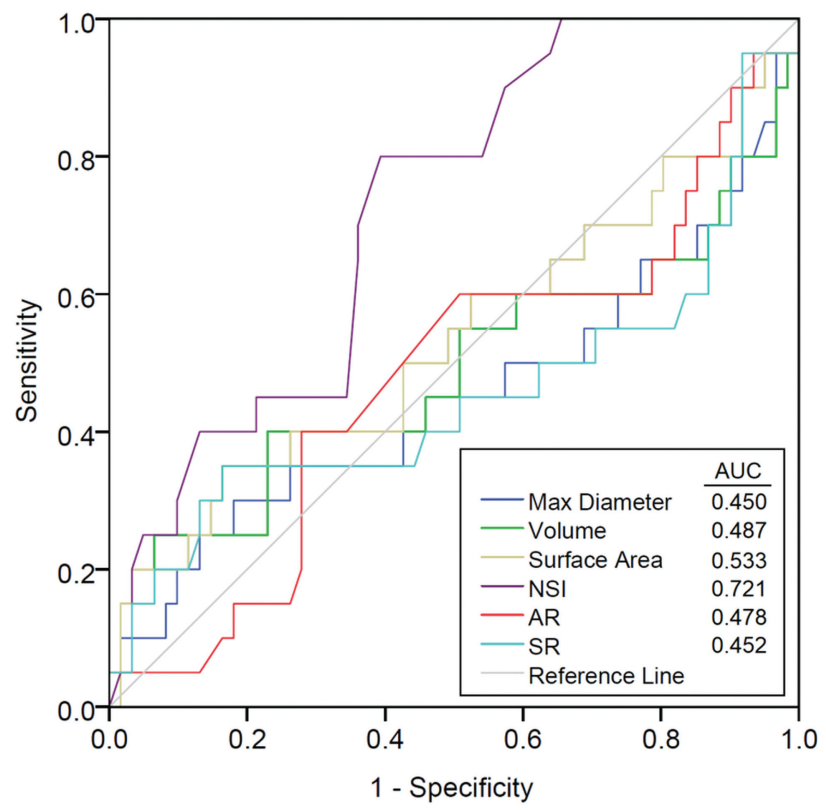

FIG 3. Receiver operating characteristic curves for each of the indices included in the study, for all imaging studies, and the initial imaging study only. Area under the curve values are listed in the legends. The NSI provides the best discrimination between growing and stable aneurysms (area under the curve $=0.712$ for all imaging studies, and area under the curve $=0.721$ for the initial imaging study). AR indicates aspect ratio; SR, size ratio; max, maximum.

rysms is relatively rapid, such assessments can be scaled for multicenter studies or clinical practice. Future work will combine morphologic indices like the NSI with more detailed epidemiologic analysis.

\section{Limitations}

Because this was a single-center retrospective study, it has bias, including existing treatment preferences, such as anatomic location and type, which results in censoring of data. In addition, the

Table 3: Index values for growing and stable aneurysms segregated by location ${ }^{2}$

\begin{tabular}{lccc}
\hline Index & ACA & ICA & PcomA \\
\hline $\begin{array}{l}\text { Maximum diameter } \\
\text { Growing }\end{array}$ & $4.66 \pm 2.63$ & $3.86 \pm 1.45$ & $5.20 \pm 2.85$ \\
$\quad$ Stable & $3.76 \pm 1.77$ & $4.36 \pm 1.88$ & $4.05 \pm 1.30$ \\
Volume & & & \\
$\quad$ Growing & $71.8 \pm 69.6$ & $85.5 \pm 175$ & $260 \pm 324$ \\
$\quad$ Stable & $47.2 \pm 45.8$ & $51.9 \pm 99.7$ & $82.6 \pm 102$ \\
Surface area & & & \\
$\quad$ Growing & $75.2 \pm 60.7$ & $87.5 \pm 116$ & $202 \pm 192$ \\
$\quad$ Stable & $57.3 \pm 38.9$ & $68.5 \pm 65.4$ & $105 \pm 91.8$ \\
NSI & & & \\
$\quad$ Growing & $0.31 \pm 0.11^{\mathrm{b}, \mathrm{c}}$ & $0.38 \pm 0.12$ & $0.39 \pm 0.08$ \\
$\quad$ Stable & $0.22 \pm 0.07^{\mathrm{b}}$ & $0.31 \pm 0.12$ & $0.45 \pm 0.08$ \\
Aspect ratio & & & \\
$\quad$ Growing & $0.95 \pm 0.25$ & $0.90 \pm 0.40$ & $0.98 \pm 0.29$ \\
$\quad$ Stable & $1.17 \pm 0.39$ & $0.96 \pm 0.33$ & $0.73 \pm 0.25$ \\
Size ratio & & & \\
$\quad$ Growing & $1.53 \pm 1.09$ & $0.93 \pm 0.55$ & $1.40 \pm 0.86^{\mathrm{b}, \mathrm{c}}$ \\
$\quad$ Stable & $1.48 \pm 0.75$ & $1.03 \pm 0.50$ & $0.81 \pm 0.33^{\mathrm{b}}$ \\
\hline
\end{tabular}

${ }^{a}$ Data are presented as mean $\pm S D$.

${ }^{\mathrm{b}}$ Significant difference between groups.

${ }^{c} p<.01$.

Table 4: Index values for growing and stable aneurysms segregated by aneurysm type ${ }^{a}$

\begin{tabular}{lcc}
\hline & Bifurcation $(\boldsymbol{n}=\mathbf{1 6})$ & Sidewall $(\boldsymbol{n}=\mathbf{7 7})$ \\
\hline Max diameter & & \\
$\quad$ Growing & $4.19 \pm 1.68$ & $3.93 \pm 2.21$ \\
$\quad$ Stable & $3.96 \pm 2.16$ & $4.18 \pm 1.79$ \\
Volume & & \\
$\quad$ Growing & $54.8 \pm 52.5$ & $122 \pm 214$ \\
$\quad$ Stable & $51.0 \pm 57.1$ & $58.2 \pm 114$ \\
Surface area & & \\
$\quad$ Growing & $68.9 \pm 42.9$ & $113 \pm 145$ \\
$\quad$ Stable & $62.7 \pm 51.8$ & $71.7 \pm 73.0$ \\
NSI & & \\
$\quad$ Growing & $0.31 \pm 0.10$ & $0.39 \pm 0.11^{\mathrm{b}, \mathrm{c}}$ \\
$\quad$ Stable & $0.22 \pm 0.07$ & $0.31 \pm 0.12^{\mathrm{b}}$ \\
Aspect ratio & & \\
$\quad$ Growing & $1.00 \pm 0.33$ & $1.01 \pm 0.57$ \\
$\quad$ Stable & $1.02 \pm 0.32$ & $1.02 \pm 0.41$ \\
Size ratio & & \\
$\quad$ Growing & $1.71 \pm 1.45$ & $1.11 \pm 0.77$ \\
Stable & $1.37 \pm 0.91$ & $1.15 \pm 0.62$ \\
\hline
\end{tabular}

Note:-Max indicates maximum.

${ }^{a}$ Data are presented as mean $\pm \mathrm{SD}$

${ }^{\mathrm{b}}$ Significant difference between groups.

${ }^{c} p<.01$.

sample is likely biased against aneurysms $>7 \mathrm{~mm}$ and of irregular shape because these are more frequently treated, except in circumstances such as advanced age. Such bias is likely to be present in a prospective study as well, to not endanger patient safety. Regarding the measurement method, as aneurysm size decreases, the accuracy of measurements does as well. Examination of how different CTA imaging protocols affect such measurements would be beneficial. ${ }^{26}$ Finally, as expected on the basis of the frequency of intracranial aneurysm growth after diagnosis, there are significantly more stable aneurysms than growing aneurysms in the study. This finding is further exacerbated in some of the size/ location groups and may make it more challenging to generalize the findings to the broader population. A larger, multicenter retrospective study including several years of data could address most of these issues. 


\section{CONCLUSIONS}

This study identified a significant relationship between aneurysm morphologic characteristics and growth. Specifically, the NSI was relatively consistently associated with growth in various analyses, in which it tended to be larger for aneurysms that would continue to grow. Additional shape indices such as size ratio were found to be associated with growth for particular size ranges and locations. Morphologic analysis appears to be a powerful means of identifying aneurysms likely to grow as well as a useful tool to investigate aneurysm growth, suitable for studies with many cases.

Disclosures: Aichi Chien—RELATED: Grant: Brain Aneurysm Foundation Research Grant and Society of Interventional Radiology Foundation Dr. Ernest J. Ring Academic Development Grant.* *Money paid to the institution.

\section{REFERENCES}

1. Brown RD. Unruptured intracranial aneurysms. Semin Neurol 2010;30:537-44 CrossRef Medline

2. International Study of Unruptured Intracranial Aneurysms Investigators. Unruptured intracranial aneurysms: risk of rupture and risks of surgical intervention. $N$ Engl J Med 1998;339:1725-33 CrossRef Medline

3. Villablanca JP, Duckwiler GR, Jahan R, et al. Natural history of asymptomatic unruptured cerebral aneurysms evaluated at CT angiography: growth and rupture incidence and correlation with epidemiologic risk factors. Radiology 2013;269:258-65 CrossRef Medline

4. Chien A, Liang F, Sayre J, et al. Enlargement of small, asymptomatic, unruptured intracranial aneurysms in patients with no history of subarachnoid hemorrhage: the different factors related to the growth of single and multiple aneurysms. J Neurosurg 2013;119: 190-97 CrossRef Medline

5. Backes D, Rinkel GJ, Laban KG, et al. Patient- and aneurysm-specific risk factors for intracranial aneurysm growth: a systematic review and meta-analysis. Stroke 2016;47:951-57 CrossRef Medline

6. Brinjikji W, Zhu YQ, Lanzino G, et al. Risk factors for growth of intracranial aneurysms: a systematic review and meta-analysis. AJNR Am J Neuroradiol 2016;37:615-20 CrossRef Medline

7. Bijlenga P1 Ebeling C, Jaegersberg M, et al; @neurIST Investigators. Risk of rupture of small anterior communicating artery aneurysms is similar to posterior circulation aneurysms. Stroke 2013;44: 3018-26 CrossRef Medline

8. Chien AC, Sayre J, Viñuela F. Comparative morphological analysis of the geometry of ruptured and unruptured aneurysms. Neurosurgery 2011;69:349-56 CrossRef Medline

9. Raghavan ML, Ma B, Harbaugh RE. Quantified aneurysm shape and rupture risk. J Neurosurg 2005;102:355-62 CrossRef Medline

10. Dhar S, Tremmel M, Mocco J, et al. Morphology parameters for intracranial aneurysm rupture risk assessment. Neurosurgery 2008; 63:185-96; discussion 196-97 CrossRef Medline

11. Xiang J, Natarajan SK, Tremmel M, et al. Hemodynamic-morphologic discriminants for intracranial aneurysm rupture. Stroke 2011; 42:144-52 CrossRef Medline
12. Baharoglu MI, Lauric A, Gao BL, et al. Identification of a dichotomy in morphological predictors of rupture status between sidewalland bifurcation-type intracranial aneurysms. J Neurosurg 2012;116: 871-81 CrossRef Medline

13. Cebral JR, Castro MA, Burgess JE, et al. Characterization of cerebral aneurysms for assessing risk of rupture by using patient-specific computational hemodynamics models. AJNR Am J Neuroradiol 2005;26:2550-59 Medline

14. Patti J, Viñuela F, and Chien AC. Distinct trends of pulsatility found at the necks of ruptured and unruptured aneurysms. J Neurointerv Surg 2014;6:103-07 CrossRef Medline

15. Chien A, Castro MA, Tateshima S, et al. Quantitative hemodynamic analysis of brain aneurysms at different locations. AJNR Am J Neuroradiol 2009;30:1507-12 CrossRef Medline

16. Cebral JR, Mut F, Weir J, et al. Quantitative characterization of the hemodynamic environment in ruptured and unruptured brain aneurysms. AJNR Am J Neuroradiol 2011;32:145-51 CrossRef Medline

17. Ramachandran M, Retarekar R, Raghavan ML, et al. Assessment of image-derived risk factors for natural course of unruptured cerebral aneurysms. J Neurosurg 2016;124:288-95 CrossRef Medline

18. Chien A, Lau V, Yi Q, et al. Posterior communicating artery aneurysms demonstrate faster interval growth than other growing aneurysms. Neuroradiol J 2017 Jan 1. [Epub ahead of print] CrossRef Medline

19. Ujiie H, Tachibana H, Hiramatsu O, et al. Effects of size and shape (aspect ratio) on the hemodynamics of saccular aneurysms: a possible index for surgical treatment of intracranial aneurysms. $\mathrm{Neu}$ rosurgery 1999;45:119-29; discussion 129-30 Medline

20. Tremmel M, Dhar S, Levy EI, et al. Influence of intracranial aneurysm-to-parent vessel size ratio on hemodynamics and implication for rupture: results from a virtual experimental study. Neurosurgery 2009;64:622-30; discussion 630-21 CrossRef Medline

21. Villablanca JP, Hooshi P, Martin N, et al. Three-dimensional helical computerized tomography angiography in the diagnosis, characterization, and management of middle cerebral artery aneurysms: comparison with conventional angiography and intraoperative findings. J Neurosurg 2002;97:1322-32 CrossRef Medline

22. Villablanca JP, Jahan R, Hooshi P, et al. Detection and characterization of very small cerebral aneurysms by using $2 \mathrm{D}$ and $3 \mathrm{D}$ helical CT angiography. AJNR Am J Neuroradiol 2002;23:1187-98 Medline

23. Dong B, Chien A, Mao Y, et al. Level set based surface capturing in 3D medical images. Med Image Comput Comput Assist Interv 2008; 11:162-69 Medline

24. Lederman C, Vese L, Chien A. Registration for 3D morphological comparison of brain aneurysm growth. In: Bebis G, Boyle B, Parvin $\mathrm{D}$, et al, eds. Advances in Visual Computing: 7th International Symposium, ISVC 2011, Las Vegas, NV, USA, September 26-28, 2011, Proceedings. Part I. Berlin: Springer-Verlag; 2011:392-99

25. Chien A, Sayre J. Morphologic and hemodynamic risk factors in ruptured aneurysms imaged before and after rupture. AJNR Am J Neuroradiol 2014;35:2130-35 CrossRef Medline

26. O'Meara B, Rahal JP, Lauric A, et al. Benefit of a sharp computed tomography angiography reconstruction kernel for improved characterization of intracranial aneurysms. Neurosurgery 2014; 10(Suppl 1):97-105; discussion 105 CrossRef Medline 